\title{
Innovating the Construction Life Cycle through BIM/GIS Integration: A Review
}

\author{
Giuseppe Celeste $^{1}$, Mariangela Lazoi ${ }^{2}\left(\mathbb{D}\right.$, Mattia Mangia $^{2, *}\left(\mathbb{D}\right.$ and Giovanna Mangialardi ${ }^{2}$ \\ 1 CNR, Centro Nazionale delle Ricerche, IPCF Department of Messina, 98158 Messina, Italy; \\ giuseppe.celeste@unisalento.it \\ 2 Department of Innovation Engineering, University of Salento, 73100 Lecce, Italy; \\ mariangela.lazoi@unisalento.it (M.L.); giovanna.mangialardi@unisalento.it (G.M.) \\ * Correspondence: mattia.mangia@unisalento.it
}

Citation: Celeste, G.; Lazoi, M.; Mangia, M.; Mangialardi, G.

Innovating the Construction Life Cycle through BIM/GIS Integration: A Review. Sustainability 2022, 14, 766. https://doi.org/10.3390/su14020766 Academic Editor: Antonio Caggiano

Received: 10 December 2021

Accepted: 6 January 2022

Published: 11 January 2022

Publisher's Note: MDPI stays neutral with regard to jurisdictional claims in published maps and institutional affiliations.

Copyright: (C) 2022 by the authors. Licensee MDPI, Basel, Switzerland. This article is an open access article distributed under the terms and conditions of the Creative Commons Attribution (CC BY) license (https:// creativecommons.org/licenses/by/ $4.0 /)$.

\begin{abstract}
The construction sector is in continuous evolution due to the digitalisation and integration into daily activities of the building information modelling approach and methods that impact on the overall life cycle. This study investigates the topic of BIM/GIS integration with the adoption of ontologies and metamodels, providing a critical analysis of the existing literature. Ontologies and metamodels share several similarities and could be combined for potential solutions to address BIM/GIS integration for complex tasks, such as asset management, where heterogeneous sources of data are involved. The research adopts a systematic literature review (SLR), providing a formal approach to retrieve scientific papers from dedicated online databases. The results found are then analysed, in order to describe the state of the art and suggest future research paths, which is useful for both researchers and practitioners. From the SLR, it emerged that several studies address ontologies as a promising way to overcome the semantic barriers of the BIM/GIS integration. On the other hand, metamodels (and MDE and MDA approaches, in general) are rarely found in relation to the integration topic. Moreover, the joint application of ontologies and metamodels for BIM/GIS applications is an unexplored field. The novelty of this work is the proposal of the joint application of ontologies and metamodels to perform BIM/GIS integration, for the development of software and systems for asset management.
\end{abstract}

Keywords: BIM; GIS; metamodel; ontology; review

\section{Introduction}

Buildings, cities and infrastructure are becoming increasingly complex systems [1], which bring together technical, economic and social aspects. For instance, infrastructure plays a crucial role in the development and sustainability of society [2] and, along with large buildings and cities, they are challenging projects for the AECO/FM sector (architecture, engineering, construction, operation and facility management). The construction life cycle is composed of several phases (e.g., design, operation, and management) and these are involved in constant evolution, due to process innovation [3]. Therefore, several research studies have investigated ways to overcome these challenges in the AECO/FM sector, by means of new methodologies and technologies, such as building information modelling (BIM) and GIS (geographic information systems). BIM is a widespread methodology which allows the AECO/FM sector to enhance its management of the information and its interoperability [4]. BIM should cover all the phases of a construction's life cycle but at the moment, it is mainly focused on the design phase [5]. The construction sector is calling for new skills, performance standards, interoperability, training and an IT system that covers the whole lifecycle of complex products or buildings. Furthermore, the use of innovative technologies and methodologies in AEC industry is now steadily expanding, since it has reached a high level of awareness [6]. Geographic information systems (GIS) refer, instead, 
to information systems which can handle and analyse data associated with a location on earth [7]. BIM and GIS are commonly adopted to support the AECO/FM sector, which is information intensive [8] and involves several stakeholders with different backgrounds and expertise. Regarding this, BIM and GIS aim to develop a common and shareable ground of data at the building and territorial scale, respectively. Their respective open formats, namely IFC and CityGML (an XML-based data format, the most used for 3D-GIS applications), allow the interchange of datasets between several software families. The digital model of the construction can be modelled or imported in order to get the required information for specific analysis of the construction (e.g., structural, thermal or energy analysis) or its interaction with the environment (e.g., environmental impact analysis, feasibility, policies). Moreover, the digital model can be integrated with other valuable sources of data.

BIM and GIS, along with other tools such as IoT sensors (Internet of Things) can provide a way to develop smart environments. Cesconetto et al. [9] defines smart environments as "pervasive computing systems that provide higher comfort levels on daily routines throughout interactions among smart sensors and embedded computers." With this upcoming and trending topic, including the concept of "Smart cities", the last decade has seen efforts from both the academic and professional world to implement integrated applications of BIM, GIS and other sources. However, in order to realise these solutions, high-level knowledge from both civil engineers and information technology (IT) engineers is required.

BIM allows construction components to be modelled in a 3D visual space, directly creating an instance of a class (named a "family"), such as walls, ceiling, slabs, etc., instead of drawing CAD lines which represent the element. This reflects the nature of the data model itself, which BIM and GIS software present in different modelling languages: EXPRESS and CityGML, respectively [10]. Additionally, GIS has its own data models and standards, namely the ISO 19100 family defined by the ISO/TC 211 (Technical Committee), which is based on model-driven architecture (MDA). MDA and model-driven engineering (MDE) are software design and development approaches which lead to the definition of metamodels. While these standards and specifications allow each methodology to grant internal interoperability, their well-defined structures proved to be a limitation in interoperability attempts between them. The matter known as BIM/GIS integration is still an open topic, as shown by several literature reviews about the argument, and is affected by a vagueness which led to a fragmented and disorienting scenario. In this article, metamodels are intended as described in the international Standard "Meta-Object Facility" (MOF) [11]. Compared to an instance-based approach, BIM/GIS integration at metamodel level is used to harmonise, map or converge concepts from these two elements.

The main objective of this paper is to discover and analyse BIM/GIS-based metamodels and ontologies, addressing two research questions:

- What is the state of the art of BIM/GIS integration based on metamodels and ontologies?

- Does a BIM/GIS digital system exist that is based on a metamodel and ontologies for the representation and management of assets?

Indeed, due to a scarcity of results on the "BIM/GIS metamodel" topic, this work also investigates ontologies, which share analogies with metamodels (i.e., formalisation of a knowledge domain). Furthermore, a joined-up adoption of ontologies and metamodels could provide support to the development of BIM/GIS applications and digital systems for the representation and management of assets. Although the potential of both metamodels and ontologies for software development and semantic interoperability is recognised, there is a gap in literature about their joint adoption in the BIM/GIS context.

To define the scope of this paper, a necessary literature background is provided about BIM/GIS integration in Section 2.1., MDA and MDE in Section 2.2 and ontologies in Section 2.3. After that, the research methodology of the systematic literature review (SLR) performed is described in Section 3, and the results are reported in Section 4. Finally, discussion about the gaps found, opportunities and conclusions are reported in Sections 5 and 6, respectively. 


\section{Background}

\subsection{BIM/GIS Integration}

The BIM/GIS integration is a broad and trending topic in AECO/FM-related research. This can be observed in the annual number of documents found on Scopus with the following query: "BIM", "GIS" and "Integration" (e.g., 196 in the 2015-2020 period). As stated by Beck et al. [12], the BIM/GIS Integration is an umbrella term that does not refer to a precise methodology or subject area. As can be seen from literature reviews investigating the BIM/GIS integration [12], studies developed several methods, such as model conversion [13,14] extension [15], interlinking [16] or merging [17]. In their literature review, Liu et al. [18] evaluated integration solutions by means of "EEEF" criteria, namely effectiveness, extensibility, effort and flexibility. Moreover, [18] classified BIM/GIS applications, grouping them into thematic categories, such as 3D cadastre [19], locationbased services and navigation [20], asset management [21] and so on.

Therefore, the BIM/GIS integration topic includes several approaches and several applications, without a clear pathway and with a heterogeneous understanding of the term "integration". However, one of the most relevant approaches is based on a semantic web by means of linked data and ontologies (e.g., [22,23]) which will be further explained in Section 2.3. This approach involves the convergence of several data sources, maintaining them consistently and distinctly, and it can overcome problems due to the different nature of the native data models of IFC and CityGML, as observed by [24] in the definition of a city information model (CIM). Moreover, in their literature review, Zhu et al. [25] identified the two main levels of the BIM and GIS integration: geometric and semantic, with the latter being the most complex to resolve. Therefore, the BIM/GIS integration topic is still an open argument that continuously expands with further exploration and research, due to the variety of approaches which can be adopted and the countless specialised applications which, altogether, constitute the whole AECO/FM sector.

\subsection{Model Driven Architecture and Engineering}

Model-driven architecture (MDA) was first described in 2000, by the Object Management Group (OMG), and it is an approach for software design and development that relies on linking models in order to build a complete system [26]. MDA links the abstract work of developing a model with its concretisation in code in order to automate this process. MDA provides a set of standards and guidelines, and it can be considered as a part of the broader model-driven engineering (MDE) [27], which follows the principle of "everything is a model". MDE introduces the concepts of model and metamodel, relating them with the system of which they are an abstraction. The abstraction presents a layered structure, standardised in the "Meta-Object Facility" standard by the OMG; it is subdivided into four layers, called "metalevels":

- $\quad$ M3: is the meta-object facility, the most abstract layer, and is also called the meta-metamodel. In the IFC case, the model language EXPRESS itself can be considered to be the M3 layer, according to [28];

- $\quad$ M2: also referred to as the metamodel, describes the schema used to instantiate M1 models. The IFC structure itself can be placed at this level, as well as related entities such as IfcWall or IfcDoor;

- $\quad$ M1: is the model itself, for example the package of UML schemas which are used to describe a real-world domain. As a BIM analogy, the IFC model of a construction, designed by an expert in BIM software, is a construct belonging to the M1 metalevel;

- M0: is the real-world object. In software engineering it can refer to code, in the $\mathrm{AECO} / \mathrm{FM}$ sector it is the real-world building or infrastructure.

In this paper, M2 and M1 will be addressed, in particular. M2 and M1 are two levels of abstraction directly linked in a class-instance kind of relationship.

MDE and MDA are approaches for software design with the aim to facilitate and handle the whole life cycle of information and to improve software re-usability through the abstract layer subdivision. This concept is also applicable to the BIM vision, which inherits 
these traits from the object-oriented programming and modelling (OOM) of IT technologies. M2 metamodels for BIM/GIS integration can be achieved through UML profiles, being packages that can be applied to the core UML to extend and specialise the metamodel for a specific domain. The development of a BIM/GIS metamodel provides a formal structure for software development, which can be adapted, transformed and extended according to stakeholders' needs.

\subsection{Ontology and RDF/OWL Ontology Language}

The term ontology, in computer science, refers to a special kind of information object or artefact [29]. Studer et al. [30] defined ontologies based on former ontology definitions as "a formal and explicit specification of a shared conceptualization".

In practice, ontologies can be developed using the resource description framework (RDF), a standard data model for data interchange on the web [31]. However, ontologies commonly require more expressive elements to properly describe a domain and, thus, on top of RDF the Web Ontology Language (OWL) is provided. OWL language allows more complex RDF statements and it is a formal semantic developed by the W3C consortium. The adoption of ontologies leads to the creation of formal knowledge bases from which information can be retrieved unambiguously, both from humans and other agents.

Ontologies suit large knowledge bases well and they allow for the provision of a whole overview which could not be achieved from the simple sum of the underlying clusters. For example, ontologies are used in medical science, such as the Ontology for General Medical Science [32] or the Foundational Model of Anatomy (FMA) [33].

Foundation (or top-level) ontologies are ontologies that provide the very general terms which are common across domains. They act as a common basis for domain-specific ontologies. In the AECO/FM sector, a minimal ontology is the Building Topology Ontology (BOT), which describes the core topological concepts of a building [34], and it can be combined with other general or domain-specific ontologies, such as sensor observations (e.g., SOSA ontology [35]) or IoT devices (IoT-Stream [36]).

\section{Materials and Methods}

The aim of the paper was to gather knowledge about BIM/GIS metamodels and their state of the art, by means of a systematic literature review (SLR), in order to answer the two research questions of the paper (i.e., What is the state of the art of BIM/GIS integration based on metamodels and ontologies? Does a BIM/GIS digital system exist that is based on a metamodel and ontologies for the representation and management of assets?).

The research approach followed a workflow which required several steps, inspired by former methodologies found in literature [37,38], which subdivided the whole process into sections. In this work, the review methodology was composed of three components, i.e., data collection, data analysis and conclusion. An overview of the methodology is reported in Figure 1. For the data collection phase, SLR provides an evaluation and synthesis of the existing body of knowledge about a field of research, investigated with a comprehensive and reproducible method [39]. For this purpose, the research was carried out on the online database Scopus (www.scopus.com, accessed on 30 November 2020) with a preliminary choice and combination of keywords, chosen based on the knowledge acquired by reading previous studies from several sources (e.g., Scopus, Google scholar). The list of chosen keyword is shown in Table 1. Scopus database allow to search terms with the wild card character "*", representing zero or more characters. For instance, using "ontolog" as a keyword the database will retrieve every term that starts with "ontolog" and ends in different ways, such as ontology, ontologies or ontological. 
Data collection

\section{Data analsys}

\section{Conclusion}

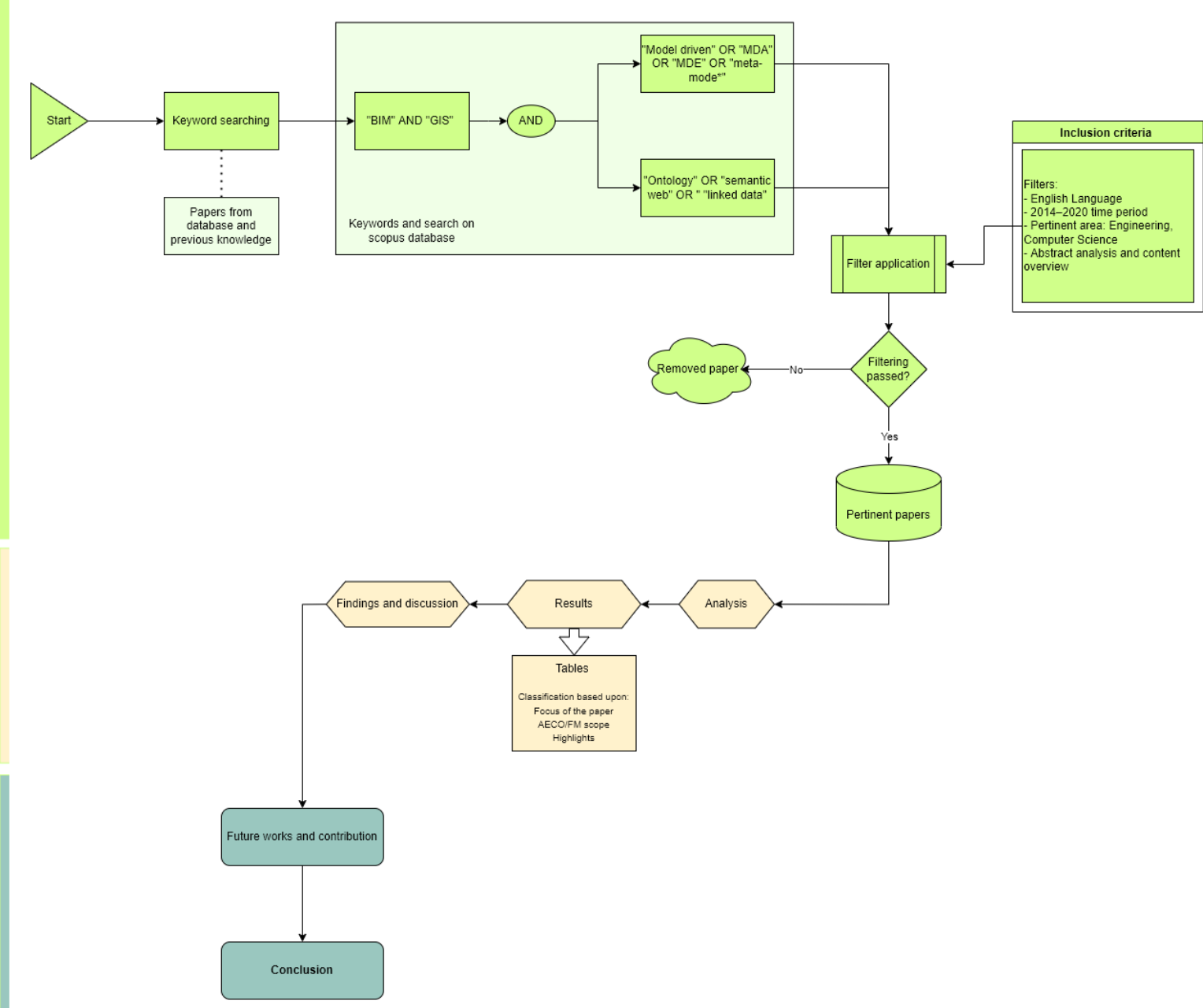

Figure 1. Research methodology for the SLR.

Table 1. Keywords used in the research.

\begin{tabular}{ll}
\hline Keywords Used in the Review & \\
\hline First query: & BIM, GIS, meta-model, model-driven, MDA, MDE. \\
\hline Second query: & BIM, GIS, ontolog*, semantic web, linked data. \\
\hline
\end{tabular}

Besides this, a set of inclusion criteria was considered in order to select only pertinent papers. The inclusion criteria required a paper to be in the English language, published in the 2014-2020 period, related to the AECO/FM sector, and retrievable. The six-year period was chosen because both BIM and GIS are trend topics in constant evolution and, for discussion purposes, articles published before 2014 would have provided outdated knowledge. In this research, both conference papers and journal articles were considered. "BIM" and "GIS" were the core of each query performed, and they were coupled with several keywords, namely "meta-model", "MDE", "MDA" and "model driven". However, only one paper was found [40]. Hence, the "GIS" keyword was removed since BIM is a more recent topic which is still in development and, for the scope of this paper, it was considered the key technology to investigate, with GIS being a complementary tool. The query typed was, according to Scopus syntax: "BIM" and "model driven", "MDA", "MDE" or "meta-model". The query retrieved 142 documents but 74 of them were related to a nonpertinent research field (e.g., pharmacology). Thus, after the exclusion of these articles and 
the restriction to the 2014-2020 period, 34 papers were retrieved. After this, an overview and abstract checking process was carried out to filter repeated or out-of-scope articles, in which the word "meta-model" was used to refer to previous specifications, such as ISO Standards [41], for example. After this last filter, only 13 papers properly addressed the M2 metamodel as defined by MOF, and they are only BIM-related, except one [40].

From the results of these queries and from the knowledge gained by the pre-study about the BIM/GIS integration background, it was found that several studies investigated the BIM/GIS integration by means of "ontology", "semantic web" and "linked data", thus these terms were used as keywords for another query including "BIM" and "GIS". This query retrieved 36 papers in the 2014-2020 period. The first filtering by title and type led to 30 articles, which were preserved even after the selection by criteria and analysis. The research took place until the 30 November 2020.

After the retrieval of pertinent papers, the next phase was to categorize and analyse the results in the data analysis phase and the discussion section. This included tables to resume papers, reporting the focus of the content, the scope in the AECO/FM sector (if any) and the main highlights found. The conclusion phase at the end provides a summary of the whole methodology, including contributions and main conclusions derived from the study.

\section{Results}

\subsection{BIM, GIS and Metamodelling}

As previously specified, the first query (i.e., "BIM" and "GIS" and "model driv" and "MDA" and "MDE" or "metamodel") retrieved only 1 article [40]. This result shows that model-driven software approaches for BIM/GIS were not explicitly found at M2 metalevel, namely the metamodel. However, as can be observed in the BIM/GIS integration background section, several authors actually developed a metamodel [13] or artefacts that can be considered metamodels but they are not clearly proposed with this term by the authors $[15,42]$. The results of the first query results are summarised in Table 2.

Regarding the selected studies, [28] carried out a broader literature review, extending to the whole MDSE in the construction industry (according to [43] this was intended as a synonym of MDE). In their literature review, Götz et al. proposed a taxonomy of the current state of the art, and from this one the authors stated that 18 out of 97 papers directly referred to technologies from MDSE, with UML as the most common one (11). Moreover, papers were also classified on the basis of the metalevel at which they were working, [28] observed that 46 papers were dealing with the M2 metalevel, which is within the scope of this article. Authors also illustrated how they considered the IFC in the four-level hierarchy of the MOF. The EXPRESS data modelling language is at the M3 metal level, and it describes the grammar used for the model product data at M2. The M1 model is given by the instances of these entities, while the M0 level is a runtime object. This structure is also found in the work conducted by [44], which adopted the MDA approach for integrating BIM into FM systems. The authors of [44] also stated that MDA, despite being utilised in such industries as health care and management, was rarely applied in the construction industry. The authors of [45] presented a different structure of the metalevel hierarchy, in which an M3 meta-meta-model was used not for EXPRESS specification but for describing basic components of buildings. The author of [40] proposed a structure of UML profiles for integration of BIM, GIS and an ITS (intelligent transport system), with the aim of establishing a harmonised approach for the use of MDA and UML. Abualdenien and Borrmann $([46,47])$ adopted MDA principles to develop a multi-LOD metamodel, which is used in several applications: vagueness visualisation, LEAC (life cycle energy assessment), structural design evaluation and a formalised communication protocol. These papers refer to the same case study, namely the Ferdinand Tausendpfund GmbH \& Co. office building (Regensburg, Germany). Perisic et al. [48], although they do not develop a metamodel they expose foundation concepts for a common ontology to support the synergy of architectural design, urban planning and construction engineering. Instead, [49] performed a model transformation, from a source model in SimModel to a target model in Modelica Library. 
Table 2. Articles found for the BIM and metamodel query.

\begin{tabular}{|c|c|c|c|c|}
\hline Number & Reference & Focus of The Paper & AECO/FM Scope & Highlights \\
\hline 1 & {$[50]$} & $\begin{array}{l}\text { Metamodel for } \\
\text { SATBIM framework }\end{array}$ & $\begin{array}{l}\text { Mechanised } \\
\text { tunnelling }\end{array}$ & $\begin{array}{l}\text { ANN trained metamodel for real-time design } \\
\text { assessment in mechanised tunnelling. The data } \\
\text { exchange workflow is automated and established } \\
\text { between a multilevel information model and the FE } \\
\text { framework KRATTOS as a simulation engine. }\end{array}$ \\
\hline 2 & [40] & $\begin{array}{l}\text { UML profiles for } \\
\text { modelling of geospatial } \\
\text { information in GIS, ITS } \\
\text { and BIM }\end{array}$ & Transport systems & $\begin{array}{l}\text { MDA approaches to develop a structure of } \\
\text { formalised UML profiles. BIM, GIS and ITS profiles } \\
\text { are all rooted to the Core Geospatial Profile (GCP) } \\
\text { based on ISO } 19103 \text { and ISO } 19109\end{array}$ \\
\hline 3 & [46] & Multi-LOD metamodel & $\begin{array}{l}\text { Vagueness } \\
\text { visualisation in } \\
\text { building models }\end{array}$ & $\begin{array}{l}\text { Uncertainties about information during building } \\
\text { design is addressed with the adoption of a } \\
\text { multi-LOD metamodel which assigns a "vagueness } \\
\text { definition" to each individual property (such as } \\
\text { material, thickness, position) }\end{array}$ \\
\hline 4 & [51] & Multi-LOD metamodel & $\begin{array}{l}\text { Management and } \\
\text { evaluation of } \\
\text { buildings in early } \\
\text { design stages }\end{array}$ & $\begin{array}{l}\text { The Multi-LOD metamodel gives explicit description } \\
\text { of LOD requirements for each building component } \\
\text { type, along with the assigned possible uncertainties } \\
\text { (which can be numerical or categorical). The model } \\
\text { evaluation focused on structural and LEAC design. }\end{array}$ \\
\hline 5 & [28] & $\begin{array}{l}\text { MDSE taxonomy for } \\
\text { construction } \\
\text { engineering }\end{array}$ & Review & $\begin{array}{l}\text { An overview on the current state of the art, in the } \\
\text { form of a taxonomy of MDSE techniques for } \\
\text { construction engineering, }\end{array}$ \\
\hline 6 & [44] & $\begin{array}{l}\text { Customised BIM } \\
\text { services and plug-ins }\end{array}$ & $\begin{array}{l}\text { Facility } \\
\text { management }\end{array}$ & $\begin{array}{l}\text { Development of a semi-automated FM system } \\
\text { factory, named EncapsulatingBIM4FM, in order to } \\
\text { achieve software interoperability with the possibility } \\
\text { of each component to evolve independently }\end{array}$ \\
\hline 7 & [47] & Multi-LOD metamodel & & Previous work of n. 3 and 4 \\
\hline 8 & [52] & Multi-LOD metamodel & & Previous work of n. 3 and 4 \\
\hline 9 & [53] & Multi-LOD metamodel & & Previous work of n. 3 and 4 \\
\hline 10 & [54] & Multi-LOD metamodel & $\begin{array}{l}\text { BIM-based } \\
\text { Communication } \\
\text { protocol }\end{array}$ & $\begin{array}{l}\text { The multi-LOD metamodel is adopted to formalise } \\
\text { LOD requirements, allowing to establish a minimised } \\
\text { communication protocol. The communication benefit } \\
\text { of the metamodel to define exchange requirements, } \\
\text { with the aim to ease and improve collaboration in } \\
\text { early phases of design. }\end{array}$ \\
\hline 11 & [55] & Multi-LOD metamodel & & Previous work of n. 3 and 4 \\
\hline 12 & [48] & $\begin{array}{l}\text { SOA for civil } \\
\text { engineering } \\
\text { cooperation }\end{array}$ & $\begin{array}{l}\text { MDSE approach for } \\
\text { a Service oriented } \\
\text { architecture (SOA) } \\
\text { based on a common } \\
\text { ontology }\end{array}$ & $\begin{array}{l}\text { Foundation of a common domain ontology for data } \\
\text { repository design }\end{array}$ \\
\hline 13 & [49] & $\begin{array}{l}\text { Building Energy } \\
\text { Performance } \\
\text { simulation }\end{array}$ & $\begin{array}{l}\text { Model } \\
\text { transformation }\end{array}$ & $\begin{array}{l}\text { Development of a model transformation system to } \\
\text { link BIM with Modelica libraries to support Building } \\
\text { Energy Performance Simulations (BEPS) }\end{array}$ \\
\hline
\end{tabular}

\subsection{BIM, GIS and Ontologies}

Ontologies can be adopted in any field of the AECO/FM sector, providing a semantic BIM/GIS integration which uplifts data on a new interoperability dimension. Widely adopted in the general AECO/FM sector, ontologies are one of the promising paths for consistent integration of BIM/GIS-based systems [18]. The results of the SLR for BIM, GIS and ontologies are summarised in Table 3. As can be seen, a particular field of the 
AECO/FM sector cannot be defined. The papers found addressed several disconnected topics, such as cultural heritage, transport systems, sustainability, safety, etc. Instead, on the applied approach, trends can be defined. The main one is the storing of BIM, GIS and other sources in the RDF/OWL format, which allows the conversion of data into machinereadable knowledge. This knowledge can store RDF triplestores, which can be queried by SPARQL endpoints [56] or, if stored in a graphic database, by NoSQL language $[57,58]$. The implementation of the conversion of IFC and GIS data to RDF/OWL requires dedicated tools, such as RDFlib and ifcOpenShell $([59,60])$. Once the BIM and GIS data are converted into ontologies, namely RDF graphs, graph matching for ontologies algorithms are applied to compare the two semantic structures and quantify the degree of similarity between them [16].

Table 3. SLR results for the BIM, GIS and ontology query.

\begin{tabular}{|c|c|c|c|c|}
\hline Number & Reference & Focus of The Paper & AECO/FM Scope & Highlights \\
\hline 1 & [56] & $\begin{array}{l}\text { Data interoperability } \\
\text { and Ontology } \\
\text { Development }\end{array}$ & General & $\begin{array}{l}\text { Development of the OSi ontology to interlink building } \\
\text { data with the geospatial data set Prime } 2 \text { of the } \\
\text { Ordnance Survey Ireland agency. The approach } \\
\text { involves the adoption of the R2RML mapping, which } \\
\text { converts relational databases in RDF triples. }\end{array}$ \\
\hline 2 & {$[61]$} & Review & Cultural Heritage & $\begin{array}{l}\text { Review for H-BIM, ontologies are considered traditional } \\
\text { ways for dealing with built heritage and can be adopted } \\
\text { for BIM query and integration with GIS }\end{array}$ \\
\hline 3 & {$[40]$} & Data interoperability & Transport systems & $\begin{array}{l}\text { Integration of information models based on MDA and } \\
\text { UML profiles, to improve interoperability between } \\
\text { BIM, GIS and intelligent transport systems (ITS) }\end{array}$ \\
\hline 4 & {$[60]$} & Ontology development & $\mathrm{N} / \mathrm{A}$ & $\begin{array}{l}\text { Proposal of a method for automatic ontology } \\
\text { generation (OGGD) from XSD documents by means of } \\
\text { transformation patterns. }\end{array}$ \\
\hline
\end{tabular}

\begin{tabular}{|c|c|c|c|c|}
\hline 5 & {$[62]$} & Data interoperability & Sustainability & $\begin{array}{l}\text { Proposal of a perspective for standardisation of } \\
\text { ontologies for AECO industries. Investigation in the } \\
\text { field of building renovation. }\end{array}$ \\
\hline 6 & {$[63]$} & Ontology development & Sustainability & $\begin{array}{l}\text { Development of a high-level ontology for urban } \\
\text { district sustainability (UDSA). }\end{array}$ \\
\hline 7 & {$[64]$} & Data interoperability & $\mathrm{N} / \mathrm{A}$ & $\begin{array}{l}\text { Presentation of mappings of explicit semantic links } \\
\text { between GIS and BIM concepts, taken from the } \\
\text { respective ISO 191XX and ISO 16739:2018 standards. }\end{array}$ \\
\hline 8 & [57] & Data interoperability & Urban Area & $\begin{array}{c}\text { Integration of CityGML and IndoorGML models and } \\
\text { conversion to JSON format for storage in graphic } \\
\text { database in a semantic web environment. }\end{array}$ \\
\hline 9 & [59] & Data interoperability & Indoor routing & $\begin{array}{c}\text { Integration of BIM and GIS for indoor routing by } \\
\text { means of integrated ontology model. The process } \\
\text { adopted the IFCOpenShell and RDFLib libraries to } \\
\text { generate the RDF/OWL entities }\end{array}$ \\
\hline 10 & [65] & Ontology Development & Built Heritage & $\begin{array}{l}\text { Proposal of a model for built cultural heritage data by } \\
\text { use of semantic web technologies and standards. }\end{array}$ \\
\hline 11 & {$[66]$} & $\begin{array}{l}\text { Data interoperability } \\
\text { and Ontology } \\
\text { Development }\end{array}$ & Infrastructure & $\begin{array}{l}\text { BIM and GIS integrated environment for highway } \\
\text { alignment, semantic web technologies were adopted } \\
\text { in a BIM/GIS interface }\end{array}$ \\
\hline 12 & {$[67]$} & Data interoperability & Asset Management & $\begin{array}{l}\text { Adoption of linked data approach for the connection } \\
\text { of BIM/GIS standards with European road object type } \\
\text { library (OTL). }\end{array}$ \\
\hline 13 & [68] & Data interoperability & $\mathrm{N} / \mathrm{A}$ & $\begin{array}{l}\text { Proposal of a method for conversion of IC geometries in } \\
\text { ifcOWL with additional GeoSPARQL, allowing the overlay } \\
\text { of IFC model with its GIS correspondent and vice versa. }\end{array}$ \\
\hline
\end{tabular}


Table 3. Cont.

\begin{tabular}{|c|c|c|c|c|}
\hline Number & Reference & Focus of The Paper & AECO/FM Scope & Highlights \\
\hline 14 & [58] & Data interoperability & Urban Mobility & $\begin{array}{c}\text { BIM/GIS integration in an RDF graph database. The } \\
\text { process adopted RDFlib and IFC to RDF Apache API, } \\
\text { and the GMO algorithm for graphic ontology } \\
\text { matching. }\end{array}$ \\
\hline 15 & [69] & Data interoperability & $\mathrm{N} / \mathrm{A}$ & $\begin{array}{l}\text { Translation of GIS data into RDF for interlinking of } \\
\text { building data. }\end{array}$ \\
\hline 16 & [18] & Review & General & $\begin{array}{l}\text { Review of BIM/GIS integration. Semantic web } \\
\text { technologies are pointed out as promising solutions } \\
\text { when compared to others. }\end{array}$ \\
\hline 17 & [70] & $\begin{array}{l}\text { Data interoperability } \\
\text { and Ontology } \\
\text { Development }\end{array}$ & $\begin{array}{l}\text { Infrastructure } \\
\quad \text { (tunnel) }\end{array}$ & $\begin{array}{l}\text { Generation of an OWL ontology similar to the } \\
\text { ifcOWL, but with the addition of tunnel and } \\
\text { infrastructure elements. The EXPRESS schema is } \\
\text { parsed by Bison and converted to an intermediate } \\
\text { representation called metamodel. }\end{array}$ \\
\hline 18 & [71] & Data interoperability & Asset Management & $\begin{array}{l}\text { A hybrid linked data approach involving BIM, GIS for } \\
\text { asset management. }\end{array}$ \\
\hline 19 & {$[72]$} & Review & General & $\begin{array}{l}\text { Investigation about the state of the art of semantic } \\
\text { web technologies in AEC industry. }\end{array}$ \\
\hline 20 & [73] & Data interoperability & Sustainability & $\begin{array}{l}\text { Urban energy modeling by semantic integration of } \\
\text { BIM and GIS, by means of ETL tool FME to convert } \\
\text { data in RDF triples and then TLF (Template Library } \\
\text { File) on energy modelling software UMI. }\end{array}$ \\
\hline 21 & [74] & Schema mapping & $\mathrm{N} / \mathrm{A}$ & $\begin{array}{l}\text { Development of reference ontology (semantic city } \\
\text { model) for BIM/GIS mapping by means of } \\
\text { instance-based method. }\end{array}$ \\
\hline 22 & [75] & Ontology Development & Safety & $\begin{array}{l}\text { Ontology for walkability in safe routes to school } \\
\text { (SRTS) based on GIS and IFC adapted files. }\end{array}$ \\
\hline 23 & [16] & Data interoperability & Safety & $\begin{array}{c}\text { Development of an integrated geospatial information } \\
\text { model (IGIM) by means of GMO for matching BIM } \\
\text { and GIS ontologies. The solution was applied to } \\
\text { evacuation planning. }\end{array}$ \\
\hline 24 & [76] & $\begin{array}{l}\text { Data interoperability } \\
\text { and Ontology } \\
\text { Development }\end{array}$ & $\mathrm{N} / \mathrm{A}$ & $\begin{array}{l}\text { Highlighting semantic web technologies as key } \\
\text { enablers for BIM-GIS integration, by means of } \\
\text { ontology construction from IFC schema. }\end{array}$ \\
\hline 25 & [77] & Ontology development & Cultural Heritage & $\begin{array}{l}\text { INCEPTION project for the development of an H-BIM } \\
\text { ontology for cultural heritage objects. }\end{array}$ \\
\hline 26 & [78] & Data interoperability & Sustainability & $\begin{array}{l}\text { Definition of the district data model (DDM) for } \\
\text { integration of BIM, GIS and energy simulation tools. } \\
\text { The DDM was part of the OptEEmAAL project and } \\
\text { involves RDF conversion of IFC and CityGML file. }\end{array}$ \\
\hline 27 & [79] & Data interoperability & General & $\begin{array}{l}\text { Integration of BIM and GIS on the semantic level } \\
\text { rather than syntactic (current practice). Case study in } \\
\text { pre-construction applications. }\end{array}$ \\
\hline 28 & [80] & $\begin{array}{l}\text { Review and Data } \\
\text { interoperability }\end{array}$ & Earthwork & $\begin{array}{l}\text { Technical review of BIM and GIS and proposal of } \\
\text { semantic web approach by means of RDF format. }\end{array}$ \\
\hline 29 & [81] & $\begin{array}{l}\text { Data interoperability } \\
\text { and Ontology } \\
\text { Development }\end{array}$ & Urban Area & $\begin{array}{l}\text { Creation of the urban information model (UIM), in } \\
\text { which information regarding urban context is } \\
\text { modelled in an ontology. }\end{array}$ \\
\hline 30 & [21] & Ontology Development & $\begin{array}{l}\text { Facility } \\
\text { management }\end{array}$ & $\begin{array}{l}\text { Facility management ontology for supply chains } \\
\text { integrated with BIM and GIS data. BIM provided } \\
\text { detailed building and asset data. }\end{array}$ \\
\hline
\end{tabular}


McGlinn et al. [56] generated the OSi ontology for publishing authoritative geospatial data in Ireland, starting from the analysis of an existing data set, in order to assess the appropriate mapping and possibility of adopting other available ontologies. In fact, one of the strong points of ontologies is that they can be joined to extend the mapped domain and express other concepts. One unique paper [40] can be found in the metamodel and ontology query performed in this SLR. The work of Jetlund is focused on the study of UML profiles for harmonisation with the MDA approach in GIS, BIM and ITS (intelligent transport system). UML profiles are specifications of the UML language and they belong to the M2 metamodel level. Mirarchi et al. [62] points out that although semantic web technologies are an emerging trend in the AECO/FM sector, even if some notable works have been carried out $([82,83])$, they are still not considered to be standard methods for information exchange in the sector. Therefore, in the BIM4EEB project, [62] proposed a standardisation and harmonisation for ontologies in the AECO industry.

Usmani et al. [60] proposed a python-based solution prototype, named OGGD (ontology generation for geospatial data), for the automatic transformation of XSD schemas to OWL models for BIM and GIS (with ifcXML and CityGML files). The authors of [63], instead, developed the UDSA (urban district ontology assessment) from a reconciliation work of 61 frameworks and ontologies reviewed, with the aim of highlighting the lack of consensus and the absence of a high-level conceptual ontology in this domain. The authors of [84] adopted a linked data approach to map explicit semantic links common to GIS and BIM concepts. Linked data allows humans and also machines to read and relate data ([85]. Correlated to linked data is the concept of the semantic web, which is an effort to turn the Web into the Web of Data, where information is stored in RDF and OWL languages and can be processed by inference rules and queried by appropriate query languages such as SPARQL [86]. Malinverni et al. [57] adopted a NoSQL graph database, where models from sources such as 3D GIS (in CityGML or IndoorGML) or BIM can be stored and each model can be connected thanks to the ontological relationship developed in a semantic web environment. It is worth noting that these graph databases (ArangoDB was adopted in this study) do not support CityGML and IndoorGML, so a GeoJSON conversion was needed. Graphic databases and ontological models were also investigated for intelligent and realtime applications, such as intelligent urban mobility web application [58]. Ontologies can also provide support for Historic-BIM (HBIM), which frequently lacks properly defined elements in the data model of regular BIM. Regarding this, several studies $([61,65,77])$ investigated the adoption of BIM for built cultural heritage and the role of ontologies as multipurpose tools. In fact, ontologies for BIM-based built heritage applications allow us to query and model knowledge for this domain.

Application of ontologies, linked data or semantic web technologies in a BIM/GIS domain are also investigated in the infrastructure domain, for instance, for optimisation purposes in the design phase [66] or to support the life-cycle data of the asset [67]. Uplifting data, converting them from a data format to RDF and OWL, allows BIM and GIS information to be queried using SPARQL language, and to link them with other domains such as IoT sensors or smart appliances [87], or to develop a unified RDF graph, such as the integrated geospatial information model (IGIM) [16]. Among the previous literature reviews, Liu et al. [18] pointed out semantic web technologies as a promising integration solution. The authors of [72] carried out an extensive literature review of semantic web technologies over the whole AEC industry and the results were in accordance with the previous review about the effectiveness of this approach. For the BIM/GIS integration, Deng et al. [74] define their ontology as a "reference ontology", since it deals with knowledge from multiple domains and acts as a medium to facilitate interoperability. This reference ontology is called "Semantic City Model" and, with an instance-based method, it defines five levels of detail (LOD) in a mediation between CityGML's and IFC's LOD.

A common workflow which can convert BIM and GIS files in RDF store, is the adoption of ETL (extract, transform and load) tools such as FME software. Bai et al. [88] adopted FME to convert data in RDF triples and then to TFL for energy modelling with UMI software. 
This workflow was also found in BIM/GIS integration pre-studies of this paper for the conversion of IFC to CityGML files. Still on energy performance, O'Donovan et al. [68] converted ifcOWL files into GeoSPARQL, a standard for representation and querying of geospatially linked data. The resulting output can be ifcOWL or BOT files. These files extract a 2D footprint from 3D ifc files and can be aligned with other data sets in GIS representing the same building, allowing the interlinking of different datasets related to it. Ontologies were also adopted, along with BIM and GIS for indoor routing [59] and walkability routes [75]. Karan et al. conducted several studies on the BIM/GIS integration with semantic web technology [76], with the employment of ontologies in preconstruction operations [79] and facility management supply chain [21]. Compared to the metamodelling technique, ontologies, along with a linked data approach and semantic web, aim to prefer data linking rather than data merging and transformation. In the case of a BIM and GIS integration approach, this is a clear advantage, as stated by several authors $([70,74])$, due to the nature of the two data models (IFC and CityGML), which cannot be comprehensively mapped in a unique standard without data loss.

\section{Discussion}

\subsection{Lack of a Bridge between AEC and MDE Communities}

Regarding the first research question, the state of the art of BIM/GIS ontologies and BIM/GIS metamodels show two different scenarios. While BIM/GIS ontologies have already been investigated for several AECO/FM applications, on the other hand, from the state of art review of BIM, GIS and MDA/MDE (thus metamodel), it emerged that the topic has scarcely been investigated or addressed. This gap found in literature could be exploited as a future work direction, since it can be related to the widespread effort of organisations such as buildingSMART, regarding data interoperability and harmonisation. Addressing the issue of BIM/GIS integration at the metamodel level can provide a high level of abstraction strategy that at the model level cannot be evaluated. The work of Jetlund et al. [40] is a recent effort in this direction. From the literature analysis it was found that the assignment of the abstraction level of a model can be ambiguous, with different authors referring to the same conceptual construct both as a model or metamodel. In fact, Götz et al. [28] carried out research in which they assessed and classified AECO/FM-related articles dealing with MDE techniques, highlighting how several proposals made by the AECO/FM community could have been implemented and misconceptions about modelling could have been avoided.

Regarding articles found in the BIM/GIS integration topic and related literature review [12,25], it can be seen that the topic is mainly addressed by members of the AEC/FM community, and there is a slight lack of awareness about MDE-modelling tools. However, the BIM/GIS integration topic actually adopts MDE approaches, such as model conversions, transformation, mapping and extensions. Moreover, with the incoming replacement of the IFC EXPRESS data model with the IFC UML [89], a convergence between AECO/FM and software engineering members could be strengthened. Adoption of UML for both BIM and GIS, along with most national and international standards, can ease metamodel approaches. Since standardisation is a main issue found in the BIM/GIS integration, it is important to understand what the added value is of metamodels, compared to models. For instance, the multi-LOD metamodel [47] was developed to provide a means for defining a project-specific data model, incorporating formal LOD definitions for component types. The metamodel itself can be used, transformed and adapted subsequently, constituting a reference point for underlying models. Otherwise, the risk is to provide still effective data models which could result in being isolated and hard to formalize or standardize. A stronger link between MDE and AECO/FM communities is also needed to clarify terminological ambiguities which can lead to misconceptions. For example, in the first part of the literature review, the term "model driven" referred to MDA and MDE concepts, but also to the concept of an application driven by the 3D model developed with BIM tools. This issue extends to the broader topic of the BIM/GIS integration, in which Beck et al. [12] noted a lack 
of expert knowledge as being one of the challenges that need to be addressed. In fact, the vast knowledge required from both AECO/FM and IT domains is rarely possessed by individual developers and this lack of awareness leads to insufficient solutions and intensive training.

In addition to the intrinsic complexity of the matter, the terminological ambiguity contributes to hindering a mutual and smooth learning of concepts. For example, [19] unified building model (UBM) is referred to as a metamodel but [12] addressed it as a shared model, in order to differentiate it from the metalevel M2, known as "metamodel" according to MOF specifications. This observation is fundamental to not confuse the schema and instance integration approach, which are at the lower metalevel M1 and M0 of the MDA hierarchy. The metamodel approach is referred as the "unification approach", according to the ISO 11354 classification. The authors of [90], in their analytic review of previous BIM/GIS integration approaches, classified the works done by [74] and [81] as a "unification approach", therefore implying the adoption of metamodels.

However, the first query performed in this paper could not manage to retrieve these articles by means of "metamodel", "MDA" or "MDE" keywords, and they were found from previous, more general, literature investigations on the broad BIM/GIS integration topic. This shows how the matter can be easily misunderstood or missed, especially when investigated by users from the AECO/FM community who may not possess advanced IT knowledge. Therefore, the current state of the art about BIM-based metamodels is a relatively unexplored topic and suffers from a lack in the literature. Compared to previous literature works, this study proposes a novel overview and approach for the BIM/GIS integration, relying on the potential of the joint use and synergies between metamodels and ontologies, as discussed in the next section.

\subsection{Metamodels and Ontology Synergies for Digital Systems}

In the AECO/FM sector, BIM and GIS integration empowers data management and analysis capabilities, due to highly detailed and geo-located models of the assets. Acquiring, collecting and representing heterogeneous information in an interconnected environment allows the observation of elements of the assets as a collaborative and symbiotic ecosystem, allowing the construction of a new knowledge base, capable of supporting complex decision-making processes. As shown by the literature review, a digital system based on ontologies and metamodels was not found, and this answers the second research question. The definition of a BIM/GIS integrated metamodel, powered by metamodels and ontology synergies, can be used as a common environment of representation for complex infrastructure applications. A metamodel can be sided by a common ontology, enabling a transformation of information from heterogeneous sources into uniformly represented homogeneous elements. This approach allows us to achieve the following objectives:

- Seamless data integration between BIM and GIS with minimised data loss;

- Definition of methodologies for the creation and joint adoption of ontologies and metamodels for BIM/GIS integration;

- Definition of a conceptual framework to enable artificial intelligence (AI) and machine learning applications.

The creation of reference ontologies allows the harmonization of data coming from different sources, to define standards, vocabularies and the problem domain. Upon this common ground, the BIM/GIS metamodel can define the solution domain and, therefore, the functionality of the system that needs to be developed. A simple conceptual overview is shown in Figure 2. 
BIM/GIS core of a digital system for representation and management of assets
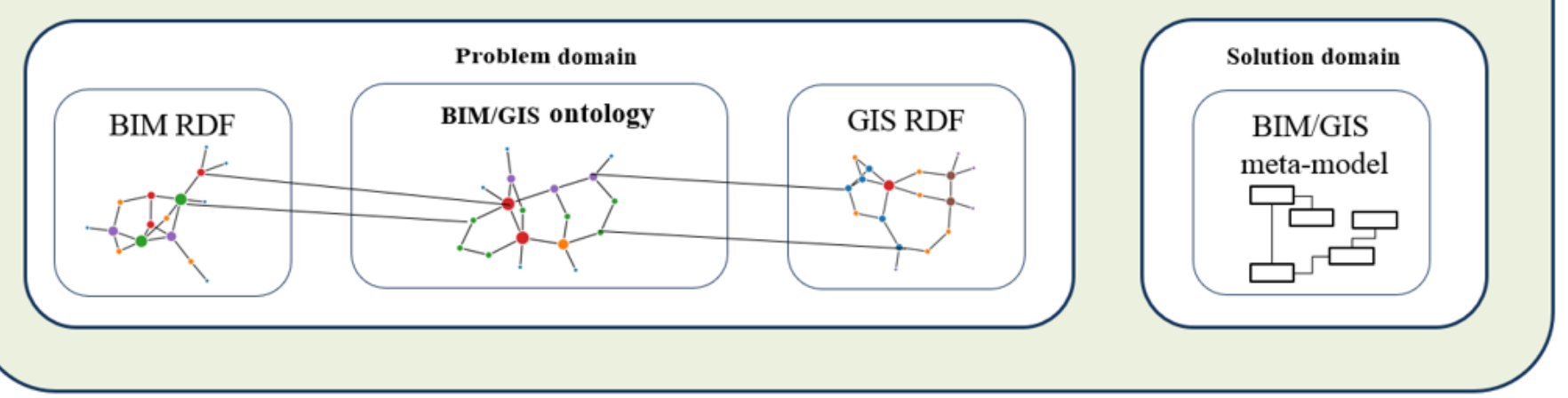

Figure 2. BIM/GIS digital system for asset representation and management.

Ontologies allow SPARQL queries because of the storage of BIM and GIS models in semantic web data formats, but they still operate in the problem domain. They give a representation of the problem, defining its classes and relationships, but to allow integration with operative applications, by means of AI and machine learning, there is a need to reach the solution domain. This is the purpose of metamodels: to define how a system operates and identify its applications. Ontologies serve as a common ground which can be modularised and queried, in order to develop clusters of knowledge bases that are understandable by every component of the integrated system while its applications can be instantiated from the metamodel, acting as a design compass for software adaptation and re-usability. These aspects need to be taken into account since each component of the system has its own standards and formats. Moreover, constant updates and changes need to be managed in order to avoid obsolescence and costly refactoring of the whole system every time. It is also worth noting that from the review, no relevant trend about a specific AECO/FM scope was found, besides the four occurrences of "sustainability" in Table 3. However, this scope, along with "Cultural Heritage" is expected to be predominant in the future. This consideration is inferred by the fact that they are both heavily semantic-based domains upon which a shared conceptualisation by means of ontologies and metamodels can be strategic to develop an effective knowledge base.

\subsection{Implications of a BIM/GIS Integration Based upon Metamodels and Ontologies}

To better understand the value and contribution of this paper, a comparison of the main activities which metamodels and ontologies can affect is described here. Companies involved in the AECO/FM industry or municipalities need to extract the highest value from data, processing and turning them into information, knowledge and wisdom. The sharing of information is crucial, along with the capability to integrate existing BIM and GIS data models with other sources (e.g., IoT sensors on buildings and infrastructures). From this perspective, a metamodel (e.g., in UML) integrating BIM- and GIS-data models allows a formalised and stored structure for software development of the company or agency to be defined, improving the re-using of software and potential expansions and contributions to new standards. At the same time, shifting BIM and GIS data to RDF or OWL allows them to be put on the same level for queries and knowledge extraction.

The adoption of this approach, involving metamodels and ontologies, can provide benefits to several users. For instance, the Research and Development division of a company can adopt metamodels to better understand how to develop software and data models linked to already existing BIM and GIS software. Ontology can be adopted to provide data in a machine-readable and interpretable way, which other stakeholders can receive and employ for their tasks (e.g., an energy expert who requires data from scenario simulations for building renovation.). Metamodels and ontologies address the domain of the discourse, from two different perspectives (i.e., solution and problem domain), and in particular, 
ontologies may constitute a knowledge base compliant with the specified formalisation defined in the metamodel. An overview of the comparison of the main activities, with and without the employment of BIM/GIS metamodels, and ontologies is provided in Table 4.

Table 4. Comparison of main activity differences between a with and without BIM/GIS metamodel and ontology scenario.

\begin{tabular}{|c|c|c|}
\hline Activity & without BIM/GIS Metamodel and Ontology & with BIM/GIS Metamodel and Ontology \\
\hline Code generation & $\begin{array}{l}\text { Hindered potential in formalising, re-using } \\
\text { and integrating code-generation activities. }\end{array}$ & $\begin{array}{l}\text { Metamodels provide a formal set of concepts and } \\
\text { relationships to which BIM and GIS data } \\
\text { models conform. }\end{array}$ \\
\hline Information processing & $\begin{array}{l}\text { The majority of information needs to be } \\
\text { interpreted by human agents. }\end{array}$ & $\begin{array}{l}\text { Software agents can interpret information and make } \\
\text { inferences, thanks to ontologies. }\end{array}$ \\
\hline $\begin{array}{l}\text { Knowledge } \\
\text { management and } \\
\text { extraction }\end{array}$ & $\begin{array}{l}\text { Knowledge is spread about data models, } \\
\text { documentation and other resources managed } \\
\text { in databases or data lakes. }\end{array}$ & $\begin{array}{l}\text { A formal knowledge base is defined and can be linked } \\
\text { or integrated with other ontologies, thanks to a } \\
\text { common language. }\end{array}$ \\
\hline Query potential & $\begin{array}{l}\text { BIM and GIS stay as separate systems or } \\
\text { integrated, human-readable information } \\
\text { systems only. }\end{array}$ & $\begin{array}{l}\text { Machine can understand the whole knowledge base } \\
\text { provided by BIM and GIS and queries can be } \\
\text { performed employing data from the two domains. }\end{array}$ \\
\hline $\begin{array}{l}\text { Integration of other } \\
\text { data models }\end{array}$ & $\begin{array}{l}\text { Complex and without a high-level construct } \\
\text { for shared compliance (i.e., metamodel). }\end{array}$ & $\begin{array}{l}\text { New concepts and relationships can be formally } \\
\text { linked and are easier to conform. }\end{array}$ \\
\hline $\begin{array}{l}\text { Complex solution } \\
\text { development }\end{array}$ & Hard to design and to implement. & $\begin{array}{l}\text { Metamodels provide the high-level structure and } \\
\text { ontologies can allow communication bridges between } \\
\text { data (e.g., sensors data linked to BIM models). }\end{array}$ \\
\hline Standardisation & $\begin{array}{l}\text { Difficult to contribute to the standardisation of } \\
\text { new data models }\end{array}$ & $\begin{array}{l}\text { Since metamodels and ontologies heavily rely upon } \\
\text { shared consensus, their development may lay the } \\
\text { foundations for new standards. }\end{array}$ \\
\hline
\end{tabular}

The perspective of a BIM/GIS integration based upon metamodels and ontologies has implications for both the academic and professional context. In fact, from the review, ontologies and metamodels are discussed separately, but for a topic in which standardisation of data is a key concept, it may be an interesting topic to investigate in future studies. An assessment of the level of knowledge about IT and knowledge management concepts (and therefore metamodels and ontology) in the AECO/FM sector may provide a starting point to address the matter. In the professional context, the issue is relevant because companies and agencies commonly deal with unharmonised and heterogenous data. Their knowledge bases need to satisfy both business needs and external standards, and the introduction of a metamodel could provide a horizontal continuum between past and future data models and a vertical continuum between international, national and company standards.

\section{Conclusions}

From this literature review, the lack of BIM-GIS metamodels is highlighted and therefore also its joint adoption with ontologies. It can be deduced that the main cause is the complexity of the matter, which involves highly specialised skills from civil, knowledge, and ICT engineering. It is also worth noting that in literature, there are some inconsistencies about what is a metamodel for the authors, leading to increasing confusion about the matter. Moreover, the BIM-GIS integration was required to overcome two intertwined challenges: solve the geometric level and the semantic one. While the first can be considered to be solved, the semantic level is still an open topic because several solutions were one-directional (mainly from BIM to GIS) or restricted to a specific application without the possibility of generalisation. The most effective BIM/GIS integration solution heavily relies on the adoption of several commercial softwares. Among the approaches for BIM/GIS integration, the adoption of linked data and ontologies were mainly investigated, because they allow effective integration without the development of a massively embracing data 
model. Ontologies allow us to perform SPARQL queries and they can be easily linked to each other. In this work, future research about the joint adoption of metamodels and ontologies for BIM/GIS applications is suggested because of their synergies and potential, addressing a gap in the literature. The described results may impact several phases of the construction life cycle, mainly the operation, maintenance and management ones. In fact, the formal definition of a system by means of the metamodel and its relationship with dedicated ontologies allows semantic interoperability to be performed and, thus, formal exchange of data and requirements between the involved stakeholders. In this way, BIM and GIS can provide data and models in a system related to the life cycle of built assets.

A limitation of this SLR is that only the Scopus database was investigated for the retrieval of articles. Moreover, the time period could be extended, although the chosen period was considered adequate by the authors, for the retrieval of the latest and mostrelevant results. The keywords for the metamodel topic were chosen to precisely address metamodels as intended by the MOF specification of the OMG. A suggestion for future works and research is to investigate the synergic adoption of ontologies and metamodels for BIM/GIS applications, since they can be considered as complementary elements. The joint synergies given by common ontologies upon which a metamodel is built are an unexplored matter in the literature. This study wants to contribute to the body of knowledge providing insights and recommendations from different perspectives. First, it wants to raise awareness about the MDA/MDE approaches for upcoming BIM/GIS-integration approaches, highlighting the link with ontologies, which are more investigated in the literature and share several analogies and potential with metamodels. Moreover, it points to the difficulties of the AECO/FM sector to become familiar with IT- and knowledgeengineering concepts. BIM introduces a brand new paradigm in the sector and it is crucial to understand its structure and standards, both in the academic and the professional context. Lately, it provides an overview about the state of the art in the literature and addresses the gap of the joint adoption of metamodels and ontologies. Their synergies have the potential to be applied to BIM/GIS digital systems for asset representation and management with a high degree of integration with other existing softwares and technologies, such as sensors and machine learning solutions. This kind of system can provide innovative features supported by both human and machine-readable data, with the aim to overcome challenges related to the management of complex assets such as infrastructures, buildings and cities.

Author Contributions: Conceptualisation, G.C. and M.M., methodology, G.C. and M.M.; validation, G.M. and M.L.; formal analysis, M.M.; investigation, M.M.; resources, M.M. and G.C.; data curation, M.M.; writing—original draft preparation, M.M. and G.C.; writing-review and editing, M.M., G.C., G.M. and M.L.; visualisation, G.M., M.L. supervision G.M., M.L.; project administration and G.C. All authors have read and agreed to the published version of the manuscript.

Funding: This research received no external funding.

Institutional Review Board Statement: Not applicable.

Informed Consent Statement: Not applicable.

Data Availability Statement: Not applicable.

Conflicts of Interest: The authors declare no conflict of interest.

\section{References}

1. Najeh, H.; Singh, M.P.; Ploix, S.; Chabir, K.; Abdelkrim, M.N. Diagnosis in buildings: New trends illustrated by an application. In Proceedings of the 2019 International Conference on Control, Automation and Diagnosis (ICCAD), Grenoble, France, 2-4 July 2019; pp. 1-6.

2. Schwab, K.; Zahidi, S. The Global Competitiveness Report: How Countries are Performing on the Road to Recovery. Available online: https:/ / www3.weforum.org/docs/WEF_TheGlobalCompetitivenessReport2020.pdf (accessed on 30 November 2020). 
3. Mattana, L.; Souza, J.C.; De Faria, M.L.T. The Study of Innovation Process in Civil Construction Through BIM Technology. In Proceedings of the International Conference on Production and Operations Management Society, 15 October 2019; Springer: Berlin/Heidelberg, Germany; pp. 771-778. Available online: https://link.springer.com/chapter/10.1007/978-3-030-23816-2_76 (accessed on 10 February 2021).

4. Sacks, R.; Eastman, C.; Lee, G.; Teicholz, P. BIM Handbook: A Guide to Building Information Modeling for Owners, Designers, Engineers, Contractors, and Facility Managers; John Wiley \& Sons: Hoboken, NI, USA, 2018.

5. Azhar, S. Building Information Modeling (BIM): Trends, benefits, risks, and challenges for the aec industry. Leadersh. Manag. Eng. 2011, 11, 241-252. [CrossRef]

6. Mangialardi, G.; Di Biccari, C.; Pascarelli, C. BIM and PLM Associations in Current Literature BIM and PLM associations in current literature. In IFIP International Conference on Product Lifecycle Management; Springer: Seville, Spain, 2017; pp. 345-357.

7. Maliene, V.; Grigonis, V.; Palevičius, V.; Griffiths, S. Geographic information system: Old principles with new capabilities. Urban Des. Int. 2011, 16, 1-6. [CrossRef]

8. Zhou, Z.; Goh, Y.M.; Shen, L. Overview and Analysis of Ontology Studies Supporting Development of the Construction Industry. J. Comput. Civ. Eng. 2016, 30, 04016026. [CrossRef]

9. Cesconetto, J.; Silva, L.A.; Bortoluzzi, F.; Navarro-Cáceres, M.; Zeferino, C.A.; Leithardt, V.R.Q. PRIPRO—Privacy Profiles: User Profiling Management for Smart Environments. Electronics 2020, 9, 1519. [CrossRef]

10. Gröger, G.; Kolbe, T.H.; Nagel, C.; Häfele, K.H. OpenGIS City Geography Markup Language (CityGML) Encoding Standard, Version 2.0.0. Available online: https: / / portal.opengeospatial.org/files/?artifact_id=47842 (accessed on 30 November 2020).

11. OMG Object Management Group. OMG Meta Object Facility (MOF) Core Specification, Version 2.5, formal/2015-06-05. Available online: Https:/ /Www.Omg.Org/ (accessed on 30 November 2020).

12. Beck, F.; Borrmann, A.; Kolbe, T.H. The need for a differentiation between heterogeneous information integration approaches in the field of "bim-gis integration": A literature review. ISPRS Ann. Photogramm. Remote. Sens. Spat. Inf. Sci. 2020, 6, 21-28. [CrossRef]

13. Stouffs, R.; Tauscher, H.; Biljecki, F. Achieving Complete and Near-Lossless Conversion from IFC to CityGML. ISPRS Int. J. Geo-Inf. 2018, 7, 355. [CrossRef]

14. Jusuf, S.K.; Mousseau, B.; Godfroid, G.; Hui, V.S.J. Integrated modeling of CityGML and IFC for city/neighborhood development for urban microclimates analysis. Energy Procedia 2017, 122, 145-150. [CrossRef]

15. El-Mekawy, M.; Östman, A.; Shahzad, K. Towards interoperating CityGML and IFC building models: A unified model based approach. In 3D Geo-Information Sciences; Springer: Berlin/Heidelberg, Germany, 2011; pp. 73-93.

16. Hor, A.-H.; Jadidi, A.; Sohn, G. Bimgis integrated geospatial information model using semantic web and rdf graphs. ISPRS Ann. Photogramm. Remote Sens. Spat. Inf. Sci. 2016, 3, 73-79. [CrossRef]

17. El-Mekawy, M.; Östman, A.; Hijazi, I. A Unified Building Model for 3D Urban GIS. ISPRS Int. J. Geo-Inf. 2012, 1, 120-145. [CrossRef]

18. Liu, X.; Wang, X.; Wright, G.; Cheng, J.C.P.; Li, X.; Liu, R. A State-of-the-Art Review on the Integration of Building Information Modeling (BIM) and Geographic Information System (GIS). ISPRS Int. J. Geo-Inf. 2017, 6, 53. [CrossRef]

19. El-Mekawy, M.; Östman, A. A unified building model for a real 3D cadastral system. In Advances in Civil and Industrial Engi-neering; IGI Global: Hershey, PA, USA, 2015; pp. 252-279.

20. $\mathrm{Wu}, \mathrm{B}$; Z Zhang, S. Integration of GIS And BIM for indoor geovisual analytics. In 23rd International Archives of the Photogrammetry, Remote Sensing and Spatial Information Sciences Congress; ISPRS Archives: Prague, Czech Republic, 2016; Volume 41, pp. 455-458.

21. Karan, E.P.; Irizarry, J. Developing a Spatial Data Framework for Facility Management Supply Chains. In Construction Research Congress 2014: Construction in a Global Network; American Society of Civil Engineers (ASCE): Reston, Virginia, 2014; pp. 2355-2364.

22. Chen, W.; Chen, K.; Cheng, J.C.P. Towards an Ontology-based Approach for Information Interoperability Between BIM and Facility Management. Adv. Comput. Strateg. Eng. 2018, 447-469. Available online: https://link.springer.com/chapter/10.1007/97 8-3-319-91638-5_25 (accessed on 30 November 2020).

23. González, E.; Piñeiro, J.D.; Toledo, J.; Arnay, R.; Acosta, L. An approach based on the ifcOWL ontology to support indoor navigation. Egypt. Inform. J. 2021, 22, 1-13. [CrossRef]

24. Ding, X.; Yang, J.; Liu, L.; Huang, W.; Wu, P. Integrating IFC and CityGML model at schema level by using linguistic and text mining techniques. IEEE Access 2020, 8, 56429-56440. [CrossRef]

25. Zhu, J.; Wright, G.; Wang, J.; Wang, X. A critical review of the integration of geographic information system and building information modelling at the data level. ISPRS Int. J. Geo-Inf. 2018, 7, 66. [CrossRef]

26. Miller, S.J.; Scott, K.; Uhl, A.; Weise, D. MDA Distilled. Available online: http:/ /www.amazon.com/MDA-Distilled-Stephen-JMiller/dp/0201788918 (accessed on 30 November 2020).

27. Bézivin, J. Model Driven Engineering: An Emerging Technical Space. Lect. Notes Comput. Sci. 2006, 4143, 36-64. [CrossRef]

28. Götz, S.; Fehn, A.; Rohde, F.; Kühn, T. Model-driven software engineering for construction engineering: Quo vadis? J. Object Technol. 2020, 19, 1-22. [CrossRef]

29. Guarino, N.; Oberle, D.; Staab, S. Handbook on Ontologies. Handb. Ontol. 2009. Available online: https://link.springer.com/ book/10.1007\%2F978-3-540-92673-3 (accessed on 10 February 2021). [CrossRef]

30. Studer, R.; Benjamins, V.; Fensel, D. Knowledge engineering: Principles and methods. Data Knowl. Eng. 1998, 25, 161-197. [CrossRef] 
31. W3C, Resource Description Framework (RDF). 2014. Available online: https:/ /www.w3.org/RDF/ (accessed on 30 November 2020).

32. BioPortal, Ontology for General Medical Science. 2020. Available online: https://bioportal.bioontology.org/ontologies/OGMS (accessed on 30 November 2020).

33. Kurt, L.R.; Mork, P.; Robinson, N.; Ravensara, S.; Emmi, A.; Calvo, F.; Stadler, D. Foundational Model of Anatomy Ontology-About. 2019. Available online: http:/ / sig.biostr.washington.edu/projects/fm/AboutFM.html (accessed on 10 February 2021).

34. W3C, Building Topology Ontology. 2021. Available online: https://w3c-lbd-cg.github.io/bot/ (accessed on 10 February 2021).

35. Janowicz, K.; Haller, A.; Cox, S.J.; Le Phuoc, D.; Lefrançois, M. SOSA: A lightweight ontology for sensors, observations, samples, and actuators. J. Web Semant. 2019, 56, 1-10. [CrossRef]

36. Elsaleh, T.; Enshaeifar, S.; Rezvani, R.; Acton, S.T.; Janeiko, V.; Bermudez-Edo, M. IoT-Stream: A Lightweight Ontology for Internet of Things Data Streams and Its Use with Data Analytics and Event Detection Services. Sensors 2020, 20, 953. [CrossRef]

37. Mohandes, S.R.; Zhang, X.; Mahdiyar, A. A comprehensive review on the application of artificial neural networks in building energy analysis. Neurocomputing 2019, 340, 55-75. [CrossRef]

38. Owolabi, T.A.; Mohandes, S.R.; Zayed, T. Investigating the impact of sewer overflow on the environment: A comprehensive literature review paper. J. Environ. Manag. 2021, 301, 113810. [CrossRef]

39. Okoli, C.; Schabram, K. A guide to conducting a systematic literature review of information systems research. SSRN Electron. J. 2010. Available online: https://ssrn.com/abstract=1954824 (accessed on 30 November 2020). [CrossRef]

40. Jetlund, K. A structure of uml profiles for modelling of geospatial information in gis, its and bim. ISPRS Ann. Photogramm. Remote. Sens. Spat. Inf. Sci. 2020, VI-4/W1-20, 101-108. [CrossRef]

41. Yilmaz, G.; Akçamete, A.; Demirors, O. A reference model for BIM capability assessments. Autom. Constr. 2019, 101, 245-263. [CrossRef]

42. Isikdag, U.; Underwood, J.; Aouad, G. An investigation into the applicability of building information models in geospatial environment in support of site selection and fire response management processes. Adv. Eng. Inf. 2008, 22, 504-519. [CrossRef]

43. Brambilla, M.; Cabot, J.; Wimmer, M. Model-driven software engineering in practice. Synth. Lect. Softw. Eng. 2012, 1, 1-182. [CrossRef]

44. Hsieh, C.-C.; Liu, C.-Y.; Wu, P.-Y.; Jeng, A.-P.; Wang, R.-G.; Chou, C.-C. Building information modeling services reuse for facility management for semiconductor fabrication plants. Autom. Constr. 2019, 102, 270-287. [CrossRef]

45. Lin, C.-Y.; Chou, C.-C. MDA-Based Facility Management Applications under BIM. 2012. Available online: https://www scopus.com/inward/record.uri?eid=2s2.084893240825\&partnerID=40\&md5=81ea99057899ac4c70496ea3d64c8d88 (accessed on 30 November 2020).

46. Abualdenien, J.; Borrmann, A. Vagueness visualization in building models across different design stages. Adv. Eng. Inform. 2020, 45, 101107. [CrossRef]

47. Abualdenien, J.; Borrmann, A. A meta-model approach for formal specification and consistent management of multi-LOD building models. Adv. Eng. Inform. 2019, 40, 135-153. [CrossRef]

48. Perisic, A.; Lazić, M.; Perisic, B.; Ana, P. The foundation for cooperative services in engineering buildings The common ontology for architectural and urban data repository modeling. In Proceedings of the 2015 IEEE 10th Jubilee International Symposium on Applied Computational Intelligence and Informatics, Timisoara, Romania, 21-23 May 2015; pp. 423-427.

49. Cao, J.; Wimmer, R.; Thorade, M.; Maile, T.; O’Donnel, J.; Rädler, J.; van Treeck, C.A. Flexible Model Transformation to Link Bim with Different Modelica Libraries for Building energy Performance Simulation. In Proceedings of the 14th International Conference of IBPSA-Building Simulation 2015, BS 2015, Conference Proceedings, Hyderabad, India, 7-9 December 2015; pp. 434-441. Available online: https: / / www.scopus.com/inward/record.uri?eid=2-s2.084976347287\&partnerID=40\&md5=82910 86c35b78aea8323b179d45dfe26 (accessed on 30 November 2020).

50. Ninic, J.; Alsahly, A.; Vonthron, A.; Bui, H.-G.; Koch, C.; König, M.; Meschke, G. From digital models to numerical analysis for mechanised tunnelling: A fully automated design-through-analysis workflow. Tunn. Undergr. Space Technol. 2021, 107, 103622. [CrossRef]

51. Abualdenien, J.; Schneider-Marin, P.; Zahedi, A.; Harter, H.; Exner, H.; Steiner, D.; Singh, M.M.; Borrmann, A.; Lang, W.; Petzold, F.; et al. Consistent management and evaluation of building models in the early design stages. J. Inf. Technol. Constr. 2020, 25, 212-232. [CrossRef]

52. Abualdenien, J.; Borrmann, A. A Multi-LOD Model Representing Fuzziness and Uncertainty of Building Information Models in Different Design Stages. In Proceedings of the 6th International Symposium on Life-Cycle Civil Engineering (IALCCE 2018), Genth, Belgium, 28-31 October 2018; pp. 495-501. Available online: https://www.scopus.com/inward/record.uri?eid=2s2.08506 3965702\&partnerID=40\&md5=d754dc4f9c4a00d569071dfd44b2dd3a (accessed on 30 November 2020).

53. Abualdenien, J.; Borrmann, A. A Multi-LOD Model for Visualizing Building Information Models' Vagueness. In Proceedings of the Computing in Civil Engineering 2019: Visualization, Information Modeling, and Simulation-Selected Papers from the ASCE International Conference on Computing in Civil Engineering, Atlanta, Georgia, 17-19 June 2019; pp. $248-255$.

54. Zahedi, A.; Abualdenien, J.; Petzold, F.; Borrmann, A. Minimized Communication Protocol Based on A Multi-LOD Meta-Model for Adaptive Detailing of BIM Models. Available online: https:/ / www.scopus.com/inward/record.uri?eid=2-s2.0-85069165726 \&partnerID=40\&md5=03be70d427665fbd5b628c8d8d40074f (accessed on 30 November 2020). 
55. Abualdenien, J.; Borrmann, A. Multi-LOD model for describing uncertainty and checking requirements in different design stages. In eWork and eBusiness in Architecture, Engineering and Construction-Proceedings of the 12th European Conference on Product and Process Modelling, ECPPM; Taylor and Francis Group plc: London, UK, 2018; pp. 187-195. Available online: https:/ / www.semanticscholar.org/paper/Multi-LOD-model-for-describing-uncertainty-and-in-Abualdenien-Borrmann/53 6e6f96133ff9537d90ac812c5a042009ad4e32 (accessed on 10 February 2021).

56. McGlinn, K.; Brennan, R.; Debruyne, C.; Meehan, A.; McNerney, L.; Clinton, E.; Kelly, P.; O'Sullivan, D. Publishing authoritative geospatial data to support interlinking of building information models. Autom. Constr. 2021, 124, 103534. [CrossRef]

57. Malinverni, E.S.; Naticchia, B.; Garcia, J.L.L.; Gorreja, A.; Uriarte, J.L.; Di Stefano, F. A semantic graph database for the interoperability of 3D GIS data. Appl. Geomat. 2020. Available online: https://link.springer.com/article/10.1007/s12518-020-003 34-3\#citeas (accessed on 10 February 2021). [CrossRef]

58. Hor, A.-H.; Sohn, G.; Claudio, P.; Jadidi, M.; Afnan, A. A semantic graph database for bim-gis integrated information model for an intelligent urban mobility web application. ISPRS Ann. Photogramm. Remote. Sens. Spat. Inf. Sci. 2018, IV-4, 89-96. [CrossRef]

59. Wang, N.; Issa, R.R.A. Ontology-Based Integration of BIM and GIS for Indoor Routing. In Construction Research Congress 2020; American Society of Civil Engineers (ASCE): Reston, Virginia, 2020; pp. 1010-1019. Available online: https:/ / www.scopus.com/ inward / record.uri?eid=2-s2.085096758553\&partnerID $=40 \&$ md5=6252ce45ea5a010be73336c8b97537ea (accessed on 30 November 2020).

60. Usmani, A.U.; Jadidi, M.; Sohn, G. Automatic ontology generation of bim and gis data. ISPRS-Int. Arch. Photogramm. Remote. Sens. Spat. Inf. Sci. 2020, XLIII-B4-2, 77-80. [CrossRef]

61. Yang, X.; Grussenmeyer, P.; Koehl, M.; Macher, H.; Murtiyoso, A.; Landes, T. Review of built heritage modelling: Integration of HBIM and other information techniques. J. Cult. Herit. 2020, 46, 350-360. [CrossRef]

62. Mirarchi, C.; Lucky, M.N.; Ciuffreda, S.; Signorini, M.; Spagnolo, S.L.; Bolognesi, C.; Daniotti, B.; Pavan, A. An approach for standardization of semantic models for building renovation processes. ISPRS-Int. Arch. Photogramm. Remote. Sens. Spat. Inf. Sci. 2020, XLIII-B4-2, 69-76. [CrossRef]

63. Kuster, C.; Hippolyte, J.-L.; Rezgui, Y. The UDSA ontology: An ontology to support real time urban sustainability assessment Adv. Eng. Softw. 2020, 140, 102731. [CrossRef]

64. Hbeich, E.; Roxin, A. Linking BIM and GIS standard ontologies with linked data. In Proceedings of the 8th Linked Data in Architecture and Construction Workshop, LDAC, CEUR-WS, Dublin, Ireland, 17-19 June 2020; Volume 2636, pp. 146-159.

65. Noor, S.; Shah, L.; Adil, M.; Gohar, N.; Saman, G.E.; Jamil, S.; Qayum, F. Modeling and representation of built cultural heritage data using semantic web technologies and building information model. Comput. Math. Organ. Theory 2019, 25, 247-270. [CrossRef]

66. Zhao, L.; Liu, Z.; Mbachu, J. Highway Alignment Optimization: An Integrated BIM and GIS Approach. ISPRS Int. J. Geo-Inf. 2019, 8, 172. [CrossRef]

67. Luiten, B.; Böhms, M.; Alsem, D.; O'Keeffe, A. Asset Information Management Using Linked Data for the Life-Cycle of Roads. In Proceedings of the 6th International Symposium on Life-Cycle Civil Engineering, IALCCE 2018, Ghent, Belgium, 28-31 October 2018; pp. 1529-1536. Available online: https://www.scopus.com/inward/record.uri?eid=2-s2.085063964668\&partnerID=40 \&md5=ff099500041546252eb5a22b299956ba (accessed on 30 November 2020).

68. O'Donovan, J.; O'Sullivan, D.; McGlinn, K. A Method for Converting IFC Geometric Data into GeoSPARQL. In CEUR Workshop Proceedings; CEUR-WS June; 2019; Volume 2389, pp. 7-20. Available online: https:/ / www.scopus.com/inward/record.uri?eid=2s2.0-85068776539\&partnerID=40\&md5=9078c6c82caacd29e0b922d19c7e1332 (accessed on 30 November 2020).

69. McGlinn, K.; Debruyne, C.; McNerney, L.; O'Sullivan, D. Integrating Building Information Models with Authoritative Irish Geospatial Information. In Proceedings of the 2017 ISWC Posters and Demonstrations and Industry Tracks, ISWC-P and DIndustry 2017, Semantic Web Science Association. Vienna, Austria, 23-27 October 2017; Volume 1963. Available online: https: / / www.scopus.com/inward / record.uri?eid=2-s2.0-85033468242\&partnerID=40\&md5=73c8af167d9ea4d47f8fbedfa4e9a394 (accessed on 30 November 2020).

70. Vilgertshofer, S.; Amann, J.; Willenborg, B.; Borrmann, A.; Kolbe, T.H. Linking BIM and GIS Models in Infrastructure by Example of IFC and CityGML. In Proceedings of the ASCE International Workshop on Computing in Civil Engineering, Seattle, WC, USA, 25-27 June 2017; pp. 133-140.

71. Luiten, B.; Böhms, M.; O'Keeffe, A.; van Nederveen, S.; Bakker, J.; Wikström, L. A hybrid linked data approach to support asset management. In Life-Cycle of Engineering Systems: Emphasis on Sustainable Civil Infrastructure-5th International Symposium on Life-Cycle Engineering, IALCCE 2016; CRC Press: Delft, Netherlands, 2017; pp. 648-654. Available online: https://www. scopus.com/inward/record.uri?eid=2-s2.0-85018625285\&partnerID=40\&md5=4dec5ff16dac1a550c5aff78a9c219b6 (accessed on 30 November 2020).

72. Pauwels, P.; Zhang, S.; Lee, Y.-C. Semantic web technologies in AEC industry: A literature overview. Autom. Constr. 2017, 73, 145-165. [CrossRef]

73. Bai, Y. Integrating GIS and BIM for Community Building Energy Design (T). University of British Columbia. 2016. Available online: https:/ / open.library.ubc.ca/collections/ubctheses/24/items/1.0340680 (accessed on 30 November 2020).

74. Deng, Y.; Cheng, J.C.; Anumba, C. Mapping between BIM and 3D GIS in different levels of detail using schema mediation and instance comparison. Autom. Constr. 2016, 67, 1-21. [CrossRef]

75. Kim, J.I.; Koo, B.; Suh, S.; Suh, W. Integration of BIM and GIS for formal representation of walkability for safe routes to school programs. KSCE J. Civ. Eng. 2016, 20, 1669-1675. [CrossRef] 
76. Karan, E.P.; Irizarry, J.; Haymaker, J. BIM and GIS integration and interoperability based on semantic web technology. J. Comput. Civ. Eng. 2016, 30, 04015043. [CrossRef]

77. Bonsma, P.; Bonsma, I.; Ziri, A.E.; Parenti, S.; Lerones, P.M.; Hernández, J.L.; Maietti, F.; Medici, M.; Turillazzi, B.; Iadanza, E. Inception standard for heritage bim models. In Proceedings of the Digital Heritage. Progress in Cultural Heritage: Documentation, Preservation, and Protection; Springer Science and Business Media LLC.: Nicosia, Cyprus, 2016; Volume 10058, pp. 590-599. Available online: https:/ /link.springer.com/chapter/10.1007\%2F978-3-319-48496-9_47 (accessed on 10 February 2021).

78. Costa, G.; Sicilia, A.; Lilis, G.N.; Rovas, D.; Izkara, J.L. A comprehensive ontologies-based framework to support the retrofitting design of energy-efficient districts. In Proceedings of the in eWork and eBusiness in Architecture, Engineering and ConstructionProceedings of the 11th European Conference on Product and Process Modelling, ECPPM 2016; Unpublished; pp. 673-681. Available online: https://www.taylorfrancis.com/chapters/edit/10.1201/9781315386904-101/comprehensive-ontologies-basedframework-support-retrofitting-design-energy-efficient-districts-costa-sicilia-lilis-rovas-izkara (accessed on 10 February 2021).

79. Karan, E.P.; Irizarry, J. Extending BIM interoperability to preconstruction operations using geospatial analyses and semantic web services. Autom. Constr. 2015, 53, 1-12. [CrossRef]

80. Kim, H.; Chen, Z.; Cho, C.-S.; Moon, H.; Ju, K.; Choi, W. Integration of BIM and GIS: Highway Cut and Fill Earthwork Balancing. In Proceedings of the 2015 ASCE International Workshop on Computing in Civil Engineering, IWCCE 2015, Reston, Virginia, 21-23 June 2015; pp. 468-474.

81. Mignard, C.; Nicolle, C. Merging BIM and GIS using ontologies application to urban facility management in ACTIVe3D. Comput. Ind. 2014, 65, 1276-1290. [CrossRef]

82. Pauwels, P.; Terkaj, W. Express to OWL for construction industry: Towards a recommendable and usable ifcOWL ontology. Autom. Constr. 2016, 63, 100-133. [CrossRef]

83. Beetz, J.; van Leeuwen, J.; de Vries, B. IfcOWL: A case of transforming EXPRESS schemas into ontologies. Artif. Intell. Eng. Des. Anal. Manuf. 2009, 23, 89-101. [CrossRef]

84. Hbeich, E.; Roxin, A. Linking BIM and GIS Standard Ontologies with Linked Data. Researchgate-Online. 2020. Available online: https: / / github.com/buildingSMART/ifcOWL (accessed on 20 November 2020).

85. Bizer, C.; Heath, T.; Berners-Lee, T. Linked Data-The Story So Far. Int. J. Semantic Web Inf. Syst. 2009, 5, 1-22. [CrossRef]

86. W3C, Semantic Web-W3C. 2015. Available online: https://www.w3.org/standards/semanticweb/ (accessed on 10 February 2021).

87. McGlinn, K.; Debruyne, C.; McNerney, L.; O'Sullivan, D. Integrating Ireland's Geospatial Information to Provide Authoritative Building Information Models. In Proceedings of the 13th International Conference on Predictive Models and Data Analytics in Software Engineering; ACM: New York, NY, USA, 2017; Volume 2017, pp. 57-64. Available online: https://dl.acm.org/doi/10.1 145/3132218.3132223 (accessed on 10 February 2021).

88. Bai, Y.; Zadeh, P.A.; Staub-French, S.; Pottinger, R. Integrating GIS and BIM for Community-Scale Energy Modeling. In Proceedings of the International Conference on Sustainable Infrastructure 2017: Methodology-Proceedings of the International Conference on Sustainable Infrastructure, New York, NY, USA, 26-28 October 2017; pp. 185-196.

89. BuildingSMART. BuildingSMART/NextGen-IFC. 2019. Available online: https://github.com/buildingSMART/NextGen-IFC (accessed on 25 November 2020).

90. Hbeich, E.; Roxin, A.; Bus, N. Previous BIM-GIS Integration Approaches: Analytic Review and Discussion. In EduBIM2020: 6ème Edition des Journées de L'enseignement et de la Recherche sur la Maquette Numérique et le BIM en France; Angle, France, 2020; Available online: https:/ / hal-cstb.archives-ouvertes.fr/hal-03178374 (accessed on 30 November 2020). 